\title{
ANALISIS TERHADAP IMPLEMENTASI STANDAR AKUNTANSI KEUANGAN UNTUK ENTITAS TANPA AKUNTABILITAS PUBLIK (SAK ETAP) PADA EMKM CV. M'ARS STUDIO
}

\author{
Christian Jhon Mamengko ${ }^{1}$, David Paul Elia Saerang ${ }^{2}$, Lidia M. Mawikere ${ }^{3}$ \\ ${ }^{123}$ Fakultas Ekonomi dan Bisnis, Jurusan Akuntansi Universitas Sam Ratulangi Jl. Kampus Bahu, Manado \\ 95115, Indonesia \\ E-mail : mamengko13@gmail.com
}

\begin{abstract}
ABSRACT
One indicator that can be done to support the development of an increase in the national economy is through the Micro, Small and Medium Enterprises (EMKM). This study aims to find out about the implementation of financial reporting practices at CV. M'ars Studio, know the statement of financial position at the end of the period (balance sheet), find out the income statement during the period, knowing notes to financial statements during the period, based on EMKM SAK ETAP. The object of the research is the implementation of the EMKM Financial Accounting Standards CV. M'ars Studio. This type of research is qualitative and uses descriptive qualitative methods used in this study are primary data which is data obtained through interviews conducted by researchers on owners and administrators and through direct observation on CV. M'ars Studio besides that, secondary data obtained through evidence of library and documentary studies owned by CV. M'ars Studio. Secondary data obtained through evidence of library and documentary studies owned by CV. M'ars Studio. The results of this study indicate that there are several EMKM IFRS elements that have not been implemented by CV. M'ars Studio. Statement of financial position at the end of the period (balance sheet), which is still simple so the implementation is quite good, the income statement is almost in line with the standard so that the implementation made is good, and notes to financial statements at CV. M'ars Studio have not been implemented. There are major obstacles faced in implementing SAK EMKM, namely the lack of information to the entity regarding IFRDs that apply specifically to MSMEs.
\end{abstract}

Keywords: Implementation; MSME; SAK ETAP

\section{PENDAHULUAN}

Perkembangan Perekonomian di indonesia saat ini tidak lepas dari pertumbuhan dan kemajuan usaha masyarakat, khususnya Entitas Mikro Kecil Menengah (EMKM) yang telah memberikan kontribusi yang penting dan besar dalam menyediakan lapangan pekerjaan dan pendapatan bagi masyarakat Indonesia. Adapun kebutuhan yang merupakan salah satu aspek psikologis yang menggerakkan makhluk hidup dalam aktivitas-aktivitasnya dan menjadi dasar (alasan) bagi setiap individu untuk berusaha.

Dalam rangka membantu UMKM memenuhi kebutuhan pelaporan keuanaganya, Dewan Standar Akuntansi Keuangan Ikatan Akuntan Indonesia (DSAK IAI) pada tahun 2016 telah menyusun dan mengesahkan Standar Akuntansi Keuangan Entitas Mikro, Kecil, dan Menengah (SAK EMKM). Penerbitan SAK EMKM ini adalah bentuk dukungan IAI sebagai organisasi profesi akuntan, dalam meningkatan peningkatan transparansi dan akuntabilitas pelaporan keuangan entitas, sekaligus mendorong pertumbuhan sektor UMKM di Indonesia. (IAI SAK EMKM , hal ix)

Entitas Mikro, Kecil dan Menengah (EMKM) terbukti mendorong dan meningkatkan pertumbuhan ekonomi nasional secara berkesinambungan. Kontribusi besar EMKM meliputi penciptaan lapangan kerja, penyerapan tenaga kerja dan terutama menjadi penahan saat 
terjadinya guncangan krisis ekonomi. Melihat peran penting tersebut, dibutuhkan dukungan dari seluruh pihak untuk mengembangkan dan mewujudkan EMKM yang maju, mandiri, dan modern termasuk memiliki akses pendanaan yang semakin luas ke sektor perbankan. (IAI SAK EMKM, 2016). EMKM seringkali mengalami kendala untuk mengembangkan usahanya. EMKM menghadapi berbagai kendala atau permasalahan yang disebabkan oleh 1) rendahnya pendidikan 2) kurangnya pemahaman teknologi informasi, dan 3) kendala penyusunan laporan keuangan (Muchid, 2015:32). Berdasarkan rumusan masalah, maka tujuan yang ingin dicapai dari penelitian ini yaitu untuk mengetahui bagaimana implementasi Standar Akuntansi Keuangan Untuk Entitas Tanpa Akuntabilitas Publik (SAK-ETAP) EMKM pada CV. M'ARS STUDIO.

\section{TINJAUAN PUSTAKA}

Akuntansi. Sumarsan (2016) Akuntansi adalah suatu seni untuk mengumpulkan, mengidentifikasikan, mengklasifikasikan, mencatat transaksi serta kejadian yang berhubungan dengan keuangan, sehingga dapat menghasilkan informasi yaitu laporan keuangan yang dapat digunakan oleh pihak-pihak yang berkepentingan.

Akuntansi Keuangan. Martani (2016) Akuntansi keuangan berorientasi pada pelaporan pihak eksternal. Beragamnya pihak eksternal dengan tujuan spesifik bagi masingmasing pihak membuat pihak penyusun laporan keuangan menggunakan prinsip dan asumsiasumsi dalam penyusunan laporan keuangan. Untuk itu diperlukan standar akuntansi yang dijadikan pedoman baik oleh penyusun maupun oleh pembaca laporan keuangan.

Standar Akuntansi Keuangan (SAK). Suwardjono (2017) teori akuntansi, menyatakan standar akuntansi adalah konsep, prinsip, metode, teknik, dan lainnya yang sengaja dipilih atas dasar kerangka konseptual oleh badan penyusun standar (atau yang berwenang) untuk diberlakukan dalam suatu lingkungan atau negara dan dituangkan dalam bentuk dokumen resmi guna mencapai tujuan pelaporan keuangan negara tersebut.

Standar Akuntansi Keuangan Entitas Tanpa Akuntanbilitas Publik. Ikatan Akuntan Indonesia (IAI, 2016). Standar Akuntansi Keuangan untuk Entitas Tanpa Akuntabilitas Publik (SAK ETAP) yakni untuk digunakan oleh Entitas Tanpa Akuntabilitas Publik (ETAP), yaitu entitas yang tidak memiliki akuntabilitas publik signifikan; dan menerbitkan laporan keuangan untuk tujuan umum (general purpose financial statement) bagi pengguna eksternal.

Laporan Keuangan. Hanafi dan Halim (2016) menyatakan bahwa laporan keuangan merupakan salah satu sumber informasi yang penting disamping informasi lain seperti informasi industri, kondisi perekonomian, pangsa pasar perusahaan, kualitas manajemen dan lainnya.

SAK ETAP Entitas Mikro Kecil Menengah. SAK EMKM adalah kepanjangan dari Standar Akuntansi Keuangan Entitas Mikro Kecil Menengah Makro yang dirancang secara khusus sebagai patokan standar akuntasi keuangan pada EMKM. Standar Keuangan ini disusun dan disahkan oleh IAI atau Ikatan Akuntasi Indonesia sebagai sebuah orgnasasi profesi yang menaungi seluruh akuntan di Indonesia. Cara penyajian laporan keuangan EMKM telah disusun secara rinci pada SAK EMKM yang dimana penyajiannya harus konsisten,informasi keuangan yang komparatif, serta lengkap. Minimal laporan keuangan tersebut terdiri dari Laporan posisi keuangan pada akhir periode, Laporan laba rugi selama periode,Catatan atas laporan keuangan. IAI (2016).

Komponen Laporan Keuangan EMKM. Menurut SAK - Laporan keuangan entitas meliputi:1).Laporan posisi keuangan;2).laporan laba rugi;3).catatan atas laporan keuangan.

Laporan Posisi Keuangan SAK ETAP EMKM. (SAK-EMKM bab 4 paragraf 2) Laporan posisi keuangan merupakan suatu laporan yang memberikan informasi tentang posisi keuangan perusahaan pada saat tertentu. Laporan posisi keuangan minimal mencangkup pos- 
pos berikut: 1) Kas dan setara kas; 2) Piutang usaha 3) Persediaan; 4) Aset tetap; 5) Utang usaha 6) Utang bank 7) Ekuitas.

Laporan Laba Rugi SAK ETAP EMKM. (SAK-EMKM bab 5 paragraf 2) Laporan laba rugi merupakan kinerja keuangan entitas hasil perusahaan dalam suatu periode tertentu. Laporan laba rugi dapat mencakup pos-pos sebagai berikut : (1) pendapatan; (2) beban keuangan; dan (3) beban pajak.

Catatan Atas Laporan Keuangan SAK ETAP EMKM. IAI, SAK-ETAP Bab 8 paragraf 1) menyatakan "catatan atas laporan keuangan memberikan penjelasan naratif atau rincian jumlah yang disajikan dalam laporan keuangan dan informasi pos-pos yang tidak memenuhi kriteria pengakuan dalam laporan keuangan.

Entitas Mikro, Kecil dan Menengah (EMKM). Undang-Undang Republik Indonesia nomor 20 tahun 2008 tentang Usaha Mikro, Kecil dan Menengah pada bab 1 pasal 1 menerangkan bahwa yang dimaksud dengan:

1. Usaha mikro adalah usaha produktif milik orang perorangan dan/atau badan usaha perorangan yang memenuhi kriteria Usaha Mikro sebagaimana diatur dalam UndangUndang ini.

2. Usaha Kecil adalah usaha ekonomi produktif yang berdiri sendiri, yang dilakukan oleh orang perorangan atau badan usaha yang bukan merupakan anak perusahaan atau bukan cabang perusahaan yang dimiliki, dikuasai, atau menjadi bagian baik langsung maupun tidak langsung dari usaha menengah atau usaha besar yang memenuhi kriteria usaha kecil sebagaimana dimaksud dalam undang-undang.

3. Usaha Menengah adalah usaha ekonomi produktif yang berdiri sendiri, yang dilakukan oleh orang perorangan atau badan usaha yang bukan merupakan anak perusahaan atau cabang perusahaan yang dimiliki, dikuasai, atau menjadi bagian baik langsung maupun tidak langsung dengan Usaha Kecil atau Usaha Besar dengan jumlah kekayaan bersih atau hasil penjualan tahunan sebagaimana diatur dalam Undang-Undang ini.

Undang-Undang Republik Indonesia nomor 20 tahun 2008 tentang Usaha Mikro, Kecil dan Menengah pada bab IV pasal 6 menerangkan bahwa:

1. Kriteria Usaha Mikro adalah:

1) Memiliki kekayaan bersih paling banyak Rp50.000.000,00 (lima puluh juta rupiah) tidak termasuk tanah dan bangunan tempat usaha; atau

2) Memiliki hasil penjualan tahunan paling banyak Rp300.000.000,00 (tiga ratus juta rupiah).

2. Kriteria Usaha Kecil adalah:

1) Memiliki kekayaan bersih lebih dari Rp50.000.000,00 (lima puluh juta rupiah) sampai dengan paling banyak Rp500.000.000,00 (lima ratus juta rupiah) tidak termasuk tanah dan bangunan tempat usaha; atau

2) Memiliki hasil penjualan tahunan lebih dari Rp300.000.000,00 (tiga ratus juta rupiah) sampai dengan paling banyak Rp2.500.000.000,00 (dua milyar lima ratus juta rupiah).

3. Kriteria Usaha Menengah:

1) Memiliki kekayaan bersih lebih dari Rp500.000.000,00 (lima ratus juta rupiah) sampai dengan paling banyak Rp10.000.000.000,00 (sepuluh milyar rupiah) tidak termasuk tanah dan bangunan tempat usaha; atau

2) Memiliki hasil penjualan tahunan lebih dari Rp2.500.000.000,00 (dua milyar lima ratus juta rupiah) sampai dengan paling banyak Rp50.000.000.000,00 (lima puluh milyar rupiah).

Penelitian Terdahulu. Pratiwi A, et.al., (2014) menunjukan bahwa perusahaan belum menyajikan laporan perubahan ekuitas, laporan arus kas, dan catatan atas laporan keuangan (CALK) serta terjadi inkonsistensi dalam penyajian beberapa pos pada Neraca 
yang tidak diungkapkan dalam CALK. Tamon et.al., (2016) menunjukkan bahwa isi jurnal ini adalah masih banyak ketidaksesuaian penyajian laporan dengan kedua peraturan tersebut. Bahkan terdapat beberapa laporan-laporan yang tidak yang tidak diterbitkan oleh pihak BPR CCI. Manado, padahal menurut PBI dan SAK ETAP wajib untuk diterbitkan, misalnya: persediaan, properti investasi, kewajiban, destimasih, dan masalah tenaga kerja. Takunang et.al., (2014) menunjukkan bahwa dalam pelaporan arus kas memberikan manfaat berupa informasi penerimaan dan pengeluaran kas dari aktivitas operasi dan investasi.

\section{METODE PENELITIAN}

Jenis dan sumber data. Data yang digunakan dalam penelitian ini adalah data kualitatif deskriptif dimana data yang digunakan dalam penelitian ini adalah data primer dan data sekunder. Penelitian ini juga melakukan pengumpulan data melalui wawancara, dokumentasi, dan kepustakaan.

Metode dan Proses Analisis. Metode analisis yang digunakan dalam penelitian ini adalah analisis data deskriptif kualitatif. Dalam penelitian kualitatif analisis data telah dilakukan sebelum masuk tempat penelitian, selama di tempat penelitian, dan setelah selesai melakukan penelitian. Penelitian ini membahas masalah berupa (1). Laporan posisi keuangan pada akhir periode (2). Laporan laba rugi selama periode (3). Catatan atas laporan keuangan pada akhir periode tahun 2018, M'ars Studio. Berikut ini merupakan susunan proses analasis yang akan digunakan dalam proses penelitian :

1. Tahap pertama, Peneliti mengumpulkan data melalui proses wawancara, dengan Pihak CV.M'ARS STUDIO. Mengenai analisis implementasi standar akuntansi keuangan untuk entitas tanpa akuntabilitas publik (SAK ETAP). Selain melalui proses wawancara, Peneliti juga mengambil data melalui proses studi kepustakaan, dan studi dokumentasi dalam hal ini dokumen-dokumen yang berhubungan dengan objek kajian yang akan diteliti pada CV.M'ARS STUDIO.

2. Tahap kedua, setelah data yang dibutuhkan terkumpul Peneliti akan melakukan analisis implementasi tentang (1). Laporan posisi keuangan pada akhir periode 2018 (2). Laporan laba rugi selama akhir periode 2018 (3). Catatan atas laporan keuangan akhir periode 2018. Data yang didapatkan dari hasil wawancara kemudian Peneliti membandingkan standar akuntansi keuangan untuk entitas tanpa akuntabilitas publik (SAK ETAP). dengan penerapan standar akuntansi keuangan untuk entitas tanpa akuntabilitas publik (SAK ETAP) yang ada di CV.M'ARS STUDIO sesuai fakta yang diperoleh dari wawancara dan dokumen yang ada.

3. Tahap ketiga, Peneliti menarik kesimpulan terkait analisis implementasi (1). Laporan posisi keuangan pada akhir periode 2018(2). Laporan laba rugi selama periode 2018 (3). Catatan atas laporan keuangan 2018. terhadap standar akuntansi keuangan untuk entitas tanpa akuntabilitas publik (SAK ETAP) EMKM di CV.M'ARS STUDIO.

4. Tahap keempat, Peneliti memberikan saran kepada perusahaan dalam hal ini CV.M'ARS STUDIO. dalam penerapan standar akuntansi keuangan untuk entitas tanpa akuntabilitas publik (SAK ETAP) EMKM di CV.M'ARS STUDIO.

\section{HASIL PENELITIAN DAN PEMBAHASAN}

\subsection{Hasil Penelitian}

Laporan Posisi Keuangan pada akhir periode (neraca) M'ars Studio. M'ars Studio menyebutkan dalam Tabel 1 bahwa. Neraca menyajikan aset, kewajiban, dan ekuitas suatu entitas pada suatu tanggal tertentu, yaitu akhir periode, pelaporan. Penyajian Neraca tersebut minimal harus mencakup pos-pos mengenai kas dan setara kas, piutang usaha dan piutang lainnya, persediaan, properti investasi, aset tetap, aset tidak berwujud, utang usaha dan utang lainnya, Total kewajiban, dan ekuitas. Dalam hal ini lebih jelas dapat dilihat di Tabel 1. 
Tabel 1. Neraca CV. M'ars Studio 31 Desember 2018

\begin{tabular}{|c|c|c|c|}
\hline \multicolumn{2}{|c|}{$\begin{array}{c}\text { AKTIVA } \\
\text { AKTIVA LANCAR }\end{array}$} & \multicolumn{2}{|c|}{ PASSIVA/KEWAJIBAN } \\
\hline 1. Kas & Rp. 400.000 & Utang Usaha & Rp. 118.000 .000 \\
\hline 2. Bank & Rp. 123.000 .000 & & \\
\hline \multirow[t]{3}{*}{ 3. Inventory } & Rp. .5 .000 .000 & & \\
\hline & & \multicolumn{2}{|c|}{ UTANG JANGKA PANJANG } \\
\hline & AKTIVA TAK LANCAR & $\begin{array}{l}\text { Utang Bank } \\
\text { TOTAL KEWAJIBAN }\end{array}$ & $\begin{array}{l}\text { Rp.1.628.000.000 } \\
\text { Rp.1.746.000.000 }\end{array}$ \\
\hline 1. Tanah & Rp.450.000.000 & & \\
\hline 2. Gedung & Rp.759.600.000 & & \\
\hline 3. Mesin & Rp.460.000.000 & & \\
\hline \multirow[t]{5}{*}{ 4. Peralatan } & Rp.20.000.000 & & \\
\hline & & EKUITAS & \\
\hline & & Modal & Rp.39.801.005 \\
\hline & & Laba Ditahan & Rp.31.198.995 \\
\hline & & Total Ekuitas & Rp.71.000.000 \\
\hline TOTAL AKTIVA & Rp.1.817.000.000 & $\begin{array}{l}\text { TOTAL KEWAJIBAN }+ \\
\text { EKUITAS }\end{array}$ & Rp.1.817.000.000 \\
\hline
\end{tabular}

Laporan Laba Rugi M'ars Studio. Laporan Laba Rugi yang diterbitkan M'ars Studio, terdiri dari pos-pos sebagai berikut: pendapatan, harga pokok penjualan, beban-beban keuangan, laba (rugi) neto, pengambilan pribadi dan utang karyawan, pelayanan dan ivestasi, laba bersih sebelum pajak, laba bersih setelah pajak,dan laba bersih setalah pembayaran gaji, jumlah akhir laba bersih usaha M'ars Studio sebagaimana dirangkum pada Tabel 2 Dapat dilihat lebih jelas dalam laporan laba rugi dibawah ini:

Tabel 2. Profit and Loss Statement 31 Dec 2018

\begin{tabular}{|c|c|c|}
\hline M'ars Pusat & Rp. 103.619.000 & \multirow{6}{*}{$\begin{array}{l}\text { Rp. } 200.451 .000 \\
\text { (Rp. 41.726.100) } \\
\text { Rp. } 158.724 .900\end{array}$} \\
\hline M'ars Kleak & Rp. 58.399 .000 & \\
\hline M'ars 3 & Rp. $\quad 38.433 .000$ & \\
\hline Pendapatan & & \\
\hline HPP & & \\
\hline Laba Kotor & & \\
\hline Beban Penyusutan & Rp. 2.000 .000 & \\
\hline B. Listrik & Rp. 1.800 .000 & \\
\hline B. Retribusi,bensin & Rp. 200.000 & \\
\hline B. Makan minum & Rp. 5.042.000 & \\
\hline B. Peralatan & Rp. 2.351 .000 & \\
\hline B. Gaji bulan Nov & Rp. 47.091.000 & \\
\hline Bank & Rp. 19.798 .000 & \\
\hline Penggadaian, kredit & Rp. 2.224.200 & \\
\hline \multicolumn{3}{|l|}{ Plus, Home kredit, } \\
\hline \multicolumn{3}{|l|}{ Gaya grafika } \\
\hline Pengambilan pribadi dan utang karyawan & Rp. 855.000 & \\
\hline Pelayanan dan Investasi & Rp. 25.701 .500 & \\
\hline Total Beban & & (Rp. 107.062.700) \\
\hline Laba Operasi & & Rp. 51.662.200 \\
\hline Biaya / Pendapatan Lain-lain & & Rp. - \\
\hline Laba bersih sebelum pajak & & Rp. 51.662 .200 \\
\hline Pajak Penghasilan $0.5 \%$ dr omset & & (Rp. 1.002.255) \\
\hline Laba bersih setelah pajak & & Rp. 50.659 .945 \\
\hline Pengeluaran lainnya & & (Rp.19.460.950) \\
\hline Laba bersih setelah pembayaran Gaji & & Rp. 31.198.995 \\
\hline
\end{tabular}

Sumber : M'ars Studio, 2018 
Catatan atas Laporan Keuangan M'ars Studio berbasis SAK ETAP EMKM. Dalam penelitian ini bagian analisis Implementasi terhadap Catatan atas Laporan Keuangan M'ars Studio berbasis SAK ETAP EMKM tidak dapat dijabarkan secara mendetail dikarenakan dalam data objek penelitian tidak terdapat.

\subsection{Hasil pembahasan}

Analisis Implementasi Laporan Posisi Keuangan pada akhir periode (neraca) M'ars Studio. Analisis Penelitian implementasi terhadap laporan keuangan M'ars Studio dalam Laporan posisi keuangan pada akhir periode (neraca) pada Tabel 3 menunjukkan perbedaan antara laporan keuangan akhir periode (neraca) M'ars Studio dengan laporan keuangan berbasis SAK ETAP. Yaitu : dalam pos-pos neraca M'ars Studio mencakup : Kas dan setara kas; piutang usaha ; persediaan; beban dibayar di muka; aset tetap; Liabilitas; ekuitas. Sedangkan pos-pos neraca berbasis SAK ETAP. Yaitu : . Kas dan setara kas; piutang usaha ; persediaan; beban dibayar di muka; aset tetap; akumulasi penyusutan; Liabilitas; ekuitas. Dari Tabel 3 dalam pembahasan ini dapat dilihat bahwa laporan posisi keuangan pada akhir periode (neraca) M'ars Studio belum sepenuhnya sudah dibuat sesuai SAK ETAP EMKM yang berlaku, dengan laporan yang sederhana yang dibuat perusahaan dan masih ada yang kurang yaitu belum membuat pos Penyusutan dalam Pelaporan keuangan pada akhir periode (neraca) dan adapun penempatan akun-akun yang belum sesuai yaitu pasiva/kewajiban yang seharusnya kewajiban/ekuitas. dikarenakan karyawan di bagian pencatatan keuangan kurang mengerti dikerenakan juga karyawan meraka yang bekerja membuat Laporan posisi keuangan di akhir periode harus mengerjakan hal lain ketika bekerja (Double Job).

Analisis Implementasi Laporan laba rugi selama periode berbasis SAK ETAP EMKM. Analisis Penelitian implementasi terhadap laporan keuangan M'ars Studio membahas mengenai pencatatan: Laporan laba rugi pada Tabel 4 menjukkan hasil laporan laba rugi M'ars Studio dengan laporan keuangan berbasis SAK ETAP. Yaitu : dalam pos-pos Laba rugi M'ars Studio mencakup : Pendapatan; Beban Keuangan; Beban paja, pos-pos laba rugi berbasis SAK ETAP. Yaitu : Pendapatan; Beban Keuangan; Beban pajak. Dalam pembahasan ini dapat dilihat bahwa laporan laba rugi M'ars Studio dalam pos-pos penempatan sudah sesuai dengan SAK ETAP yang berlaku, tetapi dari segi penempatan akun-akun pada laba rugi yang disajikan M'ars Studio belum sesuai penempatannya di karenakan, biaya gaji bulanan harusnya menjadi bagian di post biaya, yang bukan di kurangkan di laba bersih setelah pajak, maka dari itu perusahaan harus memperbaiki sesuai standar yang ditetapkan.

Tabel 4. Chek list Laba Rugi menurut SAK ETAP EMKM

\begin{tabular}{c|c|c}
\hline $\begin{array}{c}\text { SAK ETAP EMKM } \\
\text { POS }\end{array}$ & $\begin{array}{c}\text { SAK M'ARS STUDIO } \\
\text { Ada/Tidak }\end{array}$ & Keterangan \\
\hline Pendapatan & Ada & - \\
\hline Beban Keuangan & Ada & - \\
\hline Beban Pajak & Ada & - \\
\hline
\end{tabular}

Analisis Implementasi Catatan atas Laporan Keuangan M'ars Studio berbasis SAK ETAP EMKM. Dalam pembahasan penelitian ini bagian analisis Implementasi terhadap Catatan atas Laporan Keuangan M'ars Studio berbasis SAK ETAP EMKM tidak dapat dijabarkan secara mendetail dikarenakan dalam data objek penelitian tidak terdapat atau tidak ditemukan, catatan atas laporan keuangan M'ars Studio berbasis SAK ETAP EMKM. Maka dari itu perusahaan harus mencoba untuk membuat catatan atas laporan keuangan yang sudah di tetapkan berlaku yaitu dengan membuat catatan atas laporan keuangan yang memuat (1).Suatu pernyataan bahwa laporan keuangan telah disusun sesuai 
dengan SAK EMKM (2). Ikhtisar kebijakan akuntansi;(3). Informasi tambahan dan rincian pos tertentu yang menjelaskan transaksi penting dan material sehingga bermanfaat bagi pengguna untuk memahami laporan keuangan (IAI SAK EMKM hal 13).

\section{KESIMPULAN DAN SARAN}

\subsection{Kesimpulan}

Berdasarkan hasil analisis data implementasi terhadap laporan keuangan yang dilakukan berbasis Standar Akuntansi Keuangan Untuk Entitas Tanpa Akuntabilitas Publik (SAK-ETAP) EMKM pada CV. M'ARS STUDIO, dapat ditarik kesimpulan sebagai berikut:

1. Laporan posisi keuangan pada akhir periode (neraca) masih ada pos-pos dalam neraca yang belum semuanya terdapat dalam penerapan pada laporan keuangan di M'ars Studio dan adapun penempatan akun-akun yang belum sesuai sehingga belum terimplementasikan dengan baik

2. Laporan laba rugi selama akhir periode M'ars studio pos-pos nya sudah sesuai dengan SAK EMKM yang berlaku tetapi adapun penempatan akun-akun yang belum sesuai dengan standar yang berlaku saat ini, sehingga laba rugi yang diterapkan belum terimplementasikan dengan baik

3. Catatan atas laporan keuangan, sepenuhnya belum mengikuti SAK ETAP EMKM. Karna kurangnya informasi kepada entitas tentang pembuatan laporan keuangan yang berbasis SAK EMKM, sehingga laporan keuangan di M'ars Studio belum terimplementasikan.

\subsection{Saran}

Berdasarkan simpulan penelitian ini maka sebaiknya karyawan di M'ars Studio, diberikan pengetahuan (knowledge) yang lebih tentang pembuatan lapooran keuangan yang baik, berdasarkan SAK EMKM yang berlaku saat ini, agar dapat menyusun dan menyajikan laporan keuangan yang sesuai dengan SAK ETAP EMKM, sehingga tidak kesulitan untuk melengkapi administrasi ketika membuat pinjaman di Bank. Dan disarankan untuk peneliti yang akan meneliti kembali di dapat mengevaluasi kembali SAK ETAP EMKM yang berlaku umum .

\section{DAFTAR PUSTAKA}

Hanafi., \& Halim, (2016) Laporan Keuangan Edisi ke-5. Yogyakarta: UPP STIM YKPN.

Ikatan Akuntan Indonesia (2016). Standar Akuntansi Keuangan untuk Entitas Tanpa Akuntabilitas Publik (SAK ETAP).Dewan Standar Akuntansi Keuangan. Jakarta

Ikatan Akuntan Indonesia (IAI 2016 ). Entitas Mikro, Kecil dan Menengah (EMKM). Dewan Standar Akuntansi Keuangan. Jakarta.

Ikatan Akuntan Indonesia (IAI 2016 ) SAK-EMKM Laporan Laba Rugi. Dewan Standar Akuntansi Keuangan. Jakarta.

Ikatan Akuntan Indonesia (IAI 2016 ) SAK-ETAP. Catatan Atas Laporan Keuangan. Dewan Standar Akuntansi Keuangan. Jakarta.

Ikatan Akuntan Indonesia (IAI 2016) SAK EMKM. Kebutuhan Pokok Keuangan. Dewan Standar Akuntansi Keuangan. Jakarta.

Takunang, J. (2014). Penerapan Laporan Arus Kas Berdasarkan SAK-ETAP Pada UD. Berkat

Anugerah.,Jurnal,EMBA,https://ejournal.unsrat.ac.id/index.php/jbie/article/view/1269 7 diakses hari jumat, tanggal 20 September 2019.

Tamon, J. R., Sondakh, J. J., \& Mawikere, L. (2016). Evaluasi Penyajian Laporan Keuangan Berdasarkan SAK ETAP Pada PT. Bank Perkreditan Rakyat (BPR) Cipta Cemerlang Indonesia (CCI) Manado. Jurnal Berkala Ilmiah Efisiensi. 
https://ejournal.unsrat.ac.id/index.php/jbie/article/view/13696 diakses hari sabtu, tanggal 19 Juni 2019.

Martani, D. (2012) Akuntansi Keuangan Menengah Berbasis PSAK, Jakarta : Salema Empat Muchid, A. (2015). Penyusunan Laporan Keuangan UMKM berdasarkan Standar Akuntansi Keuangan-Entitas Tanpa Akuntabilitas Publik (SAK-ETAP) (Kasus pada UD. Mebel Novel'l di Banyuwangi). http://repository.unej.ac.id/handle/123456789/64361

Pratiwi, A. A., Sondakh, J. J \& Kalangi, L. (2014). Analisis penerapan SAK ETAP pada penyajian laporan keuangan PT. Nichindo Manado Suisan. Jurnal EMBA, 2(3), 254265. https://ejournal.unsrat.ac.id/index.php/emba/article/view/5498/5025, diakses hari selasa, tanggal 28 Mei 2019.

Sumarsan. (2013). Akuntansi Keuangan. Fakultas Ekonomi Universitas Methodist Indonesia,

Suwardjono. (2017). Teori Akuntansi https://suwardjono.staff.ugm.ac.id/kuliah/152-teoriakuntansi.html Universitas Gaja Mada Indonesia.

Undang-Undang Republik Indonesia nomor 20 tahun 2008 tentang Usaha Mikro, Kecil dan Menengah. Jakarta.

Undang-Undang Republik Indonesia nomor 20 tahun 2008 tentang Usaha Mikro, Kecil dan Menengah. Jakarta. 